Jurnal Media

Teknik dan

Sistem Industri
Jurnal Media Teknik \& Sistem Industri

Vol. 5 (no. 1) (2021) hal. $17-24$

http://jurnal.unsur.ac.id/JMTSI

\title{
Strategi Mitigasi Risiko Produktivitas Pada Proses Assembly Hospital Equipment
}

\author{
Andrie Pasca Hendradewa ${ }^{1 *}$, Adienta Mustika Ma'arij ${ }^{2}$ \\ 1,2 Program Studi Teknik Industri Universitas Islam Indonesia \\ Jl. Kaliurang Km 14.5 Sleman Yogyakarta \\ 1* andrie.pasca@uii.ac.id \\ 2215522282@students.uii.ac.id
}

\section{Risk Mitigation Strategy of Productivity in Assembly Process of Hospital Equipment}

Dikirimkan: 01, 2021. Diterima: 03, 2021. Dipublikasikan : 03, 2021.

\begin{abstract}
The rapid development of technology and industrialization demands an increasing need for strategic planning. One of the strategies needed for a company to remain competitive in the industrialized world is to increase productivity. However, practically several companies still experience difficulties in making efforts to increase productivity so that the productivity achieved is not optimal. The same thing happened at PT. Mega Andalan Kalasan, especially on the Assembly Unit of the Hospital Equipment. Where the productivity achieved cannot be categorized as optimal because it can be seen from the number of non-value added activities that occur in assembly process. Among the products produced, it is known that the Operating Table Manual product has the highest percentage of non-value added activity, which is 30\% of the total cycle time. This study aims to identify risks using the Failure Mode and Effect Analysis (FMEA) method and design a mitigation strategy as an initial effort to improve productivity by minimizing non-value added activities. The identification results show that there are 22 risks with moderate severity but high occurrence. Recommendations in the form of implementing better quality control on incoming materials are one of the strategies which capable of mitigating $40 \%$ of the risk of existing non value added activities..
\end{abstract}

Keywords - FMEA, risk mitigation, productivity, non-value added activity.

\begin{abstract}
Abstrak - Adanya perkembangan teknologi dan industrialisasi yang semakin pesat menuntut kebutuhan akan perencanaan strategi semakin meningkat. Salah satu strategi yang dibutuhkan agar sebuah perusahaan dapat tetap bersaing di dunia perindustrian adalah dengan meningkatkan produktivitas. Namun pada penerapannya, beberapa perusahaan masih mengalami kesulitan dalam melakukan upaya peningkatan produktivitas sehingga produktivitas yang dicapai belum optimal. Hal yang serupa terjadi di PT. Mega Andalan Kalasan, khususnya pada lantai kerja Assembly unit Hospital Equipment. Dimana produktivitas yang dicapai belum bisa dikatakan optimal karena terlihat dari banyaknya non value added activity yang terjadi pada proses assembly. Diantara sejumlah produk yang dihasilkan, diketahui bahwa pengerjaan produk Operating Table Manual memiliki persentase non value added activity yang tertinggi yaitu sebanyak 30\% dari total waktu siklusnya. Penelitian ini bertujuan untuk mengidentifikasi risiko dengan menggunakan metode Failure Mode and Effect Analysis (FMEA) dan merancang strategi mitigasi sebagai upaya awal untuk memperbaiki produktivitas dengan meminimalisir aktivitas non value added. Hasil identifikasi menunjukkan terdapat 22 risiko dengan tingkat severity sedang namun memiliki occurence yang tinggi. Rekomendasi berupa penerapan quality control yang lebih baik terhadap incoming material menjadi salah satu strategi yang mampu memitigasi $40 \%$ risiko aktivitas non value added yang ada.

Kata kunci- FMEA, mitigasi risiko, produktivitas, non-value added activity.
\end{abstract}

\section{PENDAHULUAN}

Adanya perkembangan teknologi dan industrialisasi yang semakin pesat menuntut kebutuhan akan perencanaan strategi semakin meningkat. Salah satu strategi yang dibutuhkan agar sebuah perusahaan dapat tetap bersaing di dunia 
perindustrian adalah dengan meningkatkan produktivitas. Produktivitas di definisikan sebagai kemampuan dalam mengoptimalkan keluaran (output) dari seluruh masukan (input) yang digunakan [1]. Semakin rendahnya tingkat produktivitas menunjukkan ketidakmampuan perusahaan dalam menjalankan proses bisnisnya, sehingga berakibat pada kerugian secara finansial.

Peningkatan produktivitas dapat dicapai dengan melakukan perbaikan proses produksi secara terus menerus untuk mengurangi pemborosan dan waktu siklus [2]. Namun pada penerapannya, beberapa perusahaan masih mengalami kesulitan dalam melakukan upaya peningkatan produktivitas sehingga produktivitas yang dicapai belum optimal. Hal yang serupa terjadi di PT. Mega Andalan Kalasan, khususnya pada lantai kerja Assembly unit Hospital Equipment. Secara keseluruhan, alur proses bisnis yang ada di dalam unit Hospital Equipment ditunjukkan pada gambar di bawah ini.

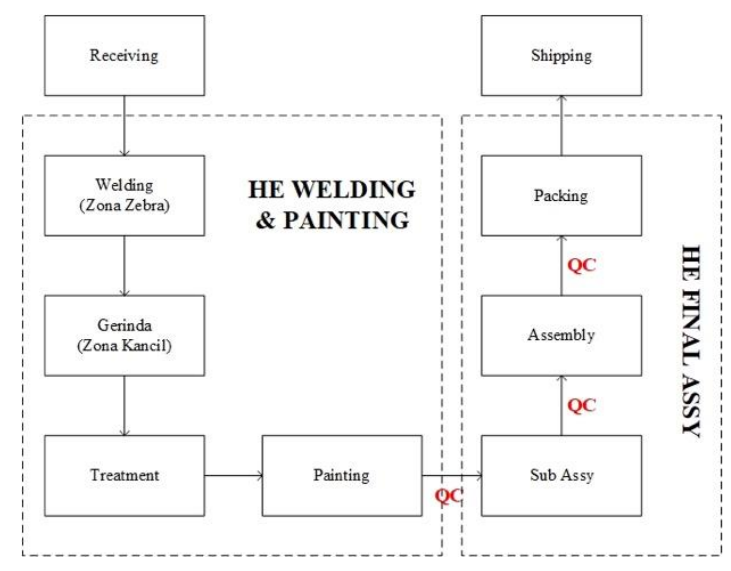

Gambar 1. Alur Proses Bisnis Unit Hospital Equipment

Alur proses bisnis yang diterapkan saat ini pada unit Hospital Equipment adalah dimulai dari penerimaan barang di SCM, kemudian dilanjutkan dengan memasuki lantai produksi welding \& painting yang berawal dari proses pengelasan (welding), gerinda, lalu treatment untuk menghilangkan karat pada material hingga masuk ke proses pengecatan (painting). Setelah proses pengecatan selesai, material memasuki lantai produksi final assy yang terdiri dari proses sub assy, assembly dan packing. Terakhir, produk jadi kemudian dikirimkan kepada konsumen.

Unit kerja assembly merupakan salah satu unit yang memiliki masalah terkait dengan cukup banyaknya kendala dalam aspek produktivitas. Berdasarkan pengukuran tahap awal melalui penghitungan waktu siklus di beberapa aktivitas assembly, didapatkan data aktivitas-aktivitas bernilai tambah atau value added activity (VA) dan juga aktivitas yang tidak bernilai tambah atau non value added activity (NVA) untuk setiap produk yang dihasilkan oleh unit Hospital Equipment.

Non value added activity (NVA) didefinisikan sebagai aktivitas yang tidak menciptakan nilai tambah. NVA merupakan aktivitas yang tidak diperlukan bagi bisnis dan pelanggan pada tingkat output dan menyebabkan beban biaya tambahan [3]. Beberapa aktivitas NVA antara lain disebabkan oleh bahan baku dan pengemasan yang tidak perlu, kualitas material yang buruk, kegagalan produksi, inventori, jam kerja yang tidak produktif [4]. Tingkat produktivitas yang dicapai pada lantai kerja assembly unit Hospital Equipment belum bisa dikatakan optimal karena terlihat dari banyaknya NVA pada proses assembly. Data persentase jumlah NVA terhadap waktu siklus dari beberapa sampel produk yang di produksi di unit Hospital Equipment PT. Mega Andalan Kalasan ditunjukkan pada Tabel I berikut.

TABEL I

PERSENTASE NVA TERHADAP WAKTU SIKLUS UNTUK BEBERAPA SAMPEL PRODUK DI UNIT HOSPITAL EQUIPMENT

\begin{tabular}{lc}
\hline \multicolumn{1}{c}{ Nama Produk } & Persentase NVA \\
\hline Operating Table Manual & $30 \%$ \\
Shelf for TV \& Refrigerator & $27 \%$ \\
Baby Basket & $20 \%$ \\
Economic Bed - Backrest with & $20 \%$ \\
Castor & $16 \%$ \\
Food Trolley M S & $15 \%$ \\
Children Bed Big & \\
\hline
\end{tabular}

Berdasarkan data di atas terlihat bahwa produk operating table manual memiliki persentase NVA tertinggi yaitu sebesar $30 \%$ dari waktu siklus, atau sekitar 3 jam dari total waktu siklus 10 jam 6 menit. Tingginya nilai NVA dari sampel produk tersebut, maka penelitian ini diprioritaskan pada langkah mitigasi atau perbaikan pada proses assembly khusus untuk produk operating table manual.

\section{Metodologi Penelitian}

Penelitian ini diawali dengan melakukan identifikasi risiko untuk mengetahui risiko apa saja yang terdapat pada proses assembly produk Operating Table Manual. Risiko menurut Griffin [5] merupakan ketidakpastian tentang peristiwa masa depan atas hasil yang diinginkan. Risiko juga dapat disebut juga sebagai peluang terjadinya bahaya, kerusakan, kehilangan, atau berbagai konsekuensi yang tidak diharapkan lainnya [6].

Identifikasi risiko dilakukan dengan melakukan observasi pada stasiun kerja assembly dan wawancara dengan tiga orang expert pada penelitian ini. Expert atau ahli yang dilibatkan dalam penelitian ini terdiri dari ahli di bidang supervisi dan operasional dengan lama bekerja di 
perusahaan tersebut minimal delapan tahun. Observasi dan wawancara dilakukan untuk mengetahui penyebab kemunculan NVA serta risiko-risiko yang berpotensi terjadi sebagai akibat dari aktivitas yang ada pada proses assembly produk operating table manual. Data yang diperoleh dari hasil wawancara berupa jenis-jenis risiko, penyebab, dan potensi dampak sistemik yang ditimbulkan. Setiap risiko yang teridentifikasi kemudian diberikan kode untuk mempermudah analisis dan visualisasi data.

Analisis risiko yang dilakukan dalam penelitian ini adalah dengan metode Failure Mode Effect Analysis (FMEA). FMEA merupakan sebuah teknik analisis kegagalan yang sudah diterapkan pada berbagai bidang dan memiliki tujuan mencermati proses maupun produk untuk mengetahui kemungkinan kegagalan yang dapat terjadi dengan mengidentifikasi potensi kegagalan, dampak serta kemungkinan munculnya [7]. FMEA selama ini telah banyak digunakan di berbagai bidang seperti dirgantara,navigasi, kimia, dan manufaktur sebagai metode untuk menganalisis reliabilitas dan teknik manajemen risiko [8]. Pada tahap ini dilakukan wawancara kepada expert terkait penyebab dan dampak dari masing-masing risiko serta mengidentifikasi langkah pengendalian yang pernah dilakukan. dilanjutkan dengan penilaian severity atau gangguan, occurence atau tingkat kejadian, dan detection atau tingkat deteksi kegagalan yang dinilai oleh expert melalui kuesioner FMEA.

Hasil analisis risiko kemudian dievaluasi untuk mengetahui urutan prioritas risiko agar memudahkan dalam proses perbaikan. Risiko diprioritaskan berdasarkan nilai Risk Priority Number (RPN) yang merupakan metode pendekatan penilaian risiko konvensional Nilai RPN didapatkan dari hasil perkalian antara severity, occurence, dan detection [9].

Menurut Mikulak dkk [7], severity diartikan sebagai penilaian seberapa besar dampak risiko mempengaruhi output proses. Dampak tersebut diberi nilai dengan skala 1 sampai 10 dimana semakin tinggi nilainya berarti semakin buruk dampaknya. Tabel kriteria pemberian nilai severity ditunjukkan pada Tabel II.

Ukuran risiko selanjutnya adalah occurence yang merupakan ukuran yang menunjukkan seberapa sering kegagalan atau risiko terjadi. Penilaian menggunakan skala 1-10 di mana semakin tinggi nilainya berarti semakin sering tingkat terjadinya risiko. Tabel kriteria penilaian occurence ditunjukkan pada Tabel III.

Selain severity dan occurence, terdapat ukuran risiko yaitu detection yang merupakan ukuran yang menunjukkan seberapa sering kegagalan/risiko terjadi. Semakin tinggi nilai detection maka semakin sering risiko terjadi. Kriteria pemberian nilai detection ditunjukkan pada Tabel IV.

$$
\text { TABEL II }
$$

KRITERIA PEMBERIAN NILAI SEVERITY

\begin{tabular}{|c|c|c|}
\hline Severity & Deskripsi & Nilai \\
\hline $\begin{array}{l}\text { Berbahaya } \\
\text { tanpa } \\
\text { peringatan }\end{array}$ & $\begin{array}{l}\text { Dapat membahayakan operator } \\
\text { (mesin atau peralatan) tanpa } \\
\text { adanya peringatan }\end{array}$ & 10 \\
\hline $\begin{array}{l}\text { Berbahaya } \\
\text { dengan } \\
\text { peringatan }\end{array}$ & $\begin{array}{l}\text { Dapat membahayakan operator } \\
\text { (mesin atau peralatan) dengan } \\
\text { adanya peringatan }\end{array}$ & 9 \\
\hline Sangat tinggi & $\begin{array}{l}\text { Seluruh }(100 \%) \text { komponen yang } \\
\text { dihasilkan tidak dapat digunakan } \\
\text { (scrap) }\end{array}$ & 8 \\
\hline Tinggi & $\begin{array}{l}\text { Sebagian }(<100 \%) \text { komponen } \\
\text { yang dihasilkan tidak dapat } \\
\text { digunakan }(\text { scrap })\end{array}$ & 7 \\
\hline \multirow[t]{2}{*}{ Sedang } & $\begin{array}{l}\text { Seluruh (100\%) komponen yang } \\
\text { dihasilkan perlu dilakukan } \\
\text { pengerjaan ulang secara off-line } \\
\text { dan diterima (rework) }\end{array}$ & 6 \\
\hline & $\begin{array}{l}\text { Sebagian }(<100 \%) \text { komponen } \\
\text { yang dihasilkan perlu dilakukan } \\
\text { pengerjaan ulang secara off-line } \\
\text { dan diterima (rework) }\end{array}$ & 5 \\
\hline \multirow[t]{2}{*}{ Rendah } & \begin{tabular}{llr}
\multicolumn{2}{l}{ Seluruh $(100 \%)$ komponen yang } \\
dihasilkan & perlu & dilakukan \\
pengerjaan & ulang & in-station \\
sebelum & menuju & proses \\
selanjutnya & &
\end{tabular} & 4 \\
\hline & 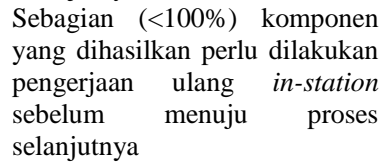 & 3 \\
\hline Minor & $\begin{array}{l}\text { Efek yang kecil pada proses, } \\
\text { operasi atau operator }\end{array}$ & 2 \\
\hline Tidak ada & Tanpa efek & 1 \\
\hline
\end{tabular}

\section{TABEL III}

KRITERIA PEMBERIAN NILAI OCCURENCE

\begin{tabular}{lll}
\hline Occurence & Deskripsi & Nilai \\
\hline Sangat tinggi & $\begin{array}{l}\text { Sangat sering terjadi ( } \geq \text { 9 dalam } \\
\text { 10 atau 90\%) }\end{array}$ & 10 \\
Tinggi & $\begin{array}{l}\text { Sering terjadi (8 dalam 10 atau } \\
80 \% \text { ) }\end{array}$ & 9 \\
& $\begin{array}{l}\text { Sering terjadi (7 dalam 10 atau } \\
70 \%)\end{array}$ & 8 \\
& $\begin{array}{l}\text { Cukup sering terjadi (6 dalam 10 } \\
\text { atau 60\%) }\end{array}$ & 7 \\
& $\begin{array}{l}\text { Jarang terjadi (5 dalam 10 atau } \\
50 \%)\end{array}$ & 6 \\
Sedang & $\begin{array}{l}\text { Jarang terjadi (4 dalam 10 atau } \\
40 \%)\end{array}$ & 5 \\
& $\begin{array}{l}\text { Jarang terjadi (3 dalam 10 atau } \\
30 \%)\end{array}$ & 4 \\
& $\begin{array}{l}\text { Cukup jarang terjadi (2 dalam 10 } \\
\text { atau 20\%) }\end{array}$ & 3 \\
Sangat jarang terjadi (1 dalam 10 & 2 \\
atau 10\%) & \\
Rendah & Hampir tidak pernah terjadi & \\
\hline $\begin{array}{l}\text { Tidak ada } \\
\text { efek }\end{array}$ &
\end{tabular}

Nilai RPN kemudian dihitung dengan mengalikan nilai severity, occurence, dan detection. Dalam hal ini, risiko yang memiliki nilai RPN 
tertinggi berarti memiliki prioritas untuk ditangani terlebih dahulu [10]. Setelah didapatkan nilai RPN kemudian dilakukan perancangan peta risiko berdasarkan nilai severity, dan occurrence.

TABEL IV

Kriteria PEMBERIAN NILAI DETECTION

\begin{tabular}{|c|c|c|}
\hline Detection & Deskripsi & Nilai \\
\hline $\begin{array}{l}\text { Tidak } \\
\text { pasti }\end{array}$ & $\begin{array}{l}\text { Pengecekan akan selalu tidak mampu } \\
\text { untuk mendeteksi penyebab potensial } \\
\text { atau mekanisme kegagalan dan mode } \\
\text { kegagalan. }\end{array}$ & 10 \\
\hline $\begin{array}{l}\text { Sangat } \\
\text { kecil }\end{array}$ & $\begin{array}{l}\text { Pengecekan memiliki kemungkinan } \\
\text { "very remote" untuk mampu } \\
\text { mendeteksi penyebab potensial atau } \\
\text { mekanisme kegagalan dan mode } \\
\text { kegagalan. }\end{array}$ & 9 \\
\hline Kecil & $\begin{array}{l}\text { Pengecekan memiliki kemungkinan } \\
\text { "remote" untuk mampu mendeteksi } \\
\text { penyebab potensial atau mekanisme } \\
\text { kegagalan dan mode kegagalan. }\end{array}$ & 8 \\
\hline $\begin{array}{l}\text { Sangat } \\
\text { rendah }\end{array}$ & $\begin{array}{l}\text { Pengecekan memiliki kemungkinan } \\
\text { sangat rendah untuk mampu } \\
\text { mendeteksi penyebab potensial } \\
\text { kegagalan dan mode kegagalan. }\end{array}$ & 7 \\
\hline Rendah & $\begin{array}{l}\text { Pengecekan memiliki kemungkinan } \\
\text { rendah untuk mampu mendeteksi } \\
\text { penyebab potensial atau mekanisme } \\
\text { kegagalan dan mode kegagalan. }\end{array}$ & 6 \\
\hline Sedang & $\begin{array}{l}\text { Pengecekan memiliki kemungkinan } \\
\text { "moderate" untuk mendeteksi } \\
\text { penyebab potensial atau mekanisme } \\
\text { kegagalan dan mode kegagalan. }\end{array}$ & 5 \\
\hline $\begin{array}{l}\text { Menengah } \\
\text { keatas }\end{array}$ & $\begin{array}{l}\text { Pengecekan memiliki kemungkinan } \\
\text { "moderately High" untuk mendeteksi } \\
\text { penyebab potensial atau mekanisme } \\
\text { kegagalan dan mode kegagalan. }\end{array}$ & 4 \\
\hline Tinggi & $\begin{array}{l}\text { Pengecekan memiliki kemungkinan } \\
\text { tinggi untuk mendeteksi penyebab } \\
\text { potensial atau mekanisme kegagalan } \\
\text { dan mode kegagalan. }\end{array}$ & 3 \\
\hline $\begin{array}{l}\text { Sangat } \\
\text { tinggi }\end{array}$ & $\begin{array}{l}\text { Pengecekan memiliki kemungkinan } \\
\text { sangat tinggi untuk mendeteksi } \\
\text { penyebab potensial atau mekanisme } \\
\text { kegagalan dan mode kegagalan. }\end{array}$ & 2 \\
\hline $\begin{array}{l}\text { Hampir } \\
\text { pasti }\end{array}$ & $\begin{array}{l}\text { Pengecekan akan selalu mendeteksi } \\
\text { penyebab potensial atau mekanisme } \\
\text { kegagalan dan mode kegagalan. }\end{array}$ & 1 \\
\hline
\end{tabular}

Setelah risiko diprioritaskan, maka perencanaan strategi mitigasi risiko adalah langkah selanjutnya yang perlu dilakukan untuk menjawab permasalahan. Dalam banyak hal, mitigasi merupakan fase dari sebuah emergency management yang berorientasi pada jangka panjang dan memiliki jangkauan yang luas [11]. Mitigasi risiko merupakan langkah yang penting sebagai upaya penyelesaian masalah yang diberikan kepada seluruh risiko yang telah teridentifikasi dan digunakan sebagai bahan pertimbangan untuk perusahaan. Perancangan usulan tindakan mitigasi dilakukan berdasarkan urutan prioritas risiko yang telah ditentukan berdasarkan RPN.

\section{HASIL PENELITIAN}

Risiko yang teridentifikasi selama proses assembly produk operating table manual kemudian dianalisis penyebab beserta nilai severity, occurrence dan detection untuk mendapatkan nilai RPN menggunakan metode FMEA. Nilai RPN kemudian digunakan sebagai dasar dalam penentuan prioritas risiko. Semakin tinggi nilai RPN maka urutan prioritasnya perbaikannya semakin tinggi. Hasil identifikasi risiko berdasarkan sub unit assembly beserta nilai severity $(\mathrm{S})$, occurence $(\mathrm{O})$, detection $(\mathrm{D})$, dan risk priority number (RPN) ditunjukkan pada Tabel V.

TABEL V

HASIL IDENTIFIKASI RISIKO BERDASARKAN SUB UNIT ASSEMBLY

\begin{tabular}{|c|c|c|c|c|c|}
\hline $\begin{array}{l}\text { Kode } \\
\text { Risiko }\end{array}$ & Risiko & $\mathbf{S}$ & $\mathbf{O}$ & D & RPN \\
\hline $\mathrm{R} 1$ & $\begin{array}{l}\text { Tap pada katub pompa } \\
\text { kurang dalam }\end{array}$ & 4 & 7 & 8 & 224 \\
\hline \multirow[t]{2}{*}{$\mathrm{R} 2$} & Proses pembuatan seal & & & & \\
\hline & $\begin{array}{l}\text { katub yang memakan } \\
\text { waktu }\end{array}$ & 4 & 8 & 5 & 160 \\
\hline R3 & Pompa bocor & 4 & 4 & 8 & 128 \\
\hline $\mathrm{R} 4$ & Rakitan as dan bum sesak & 4 & 5 & 6 & 120 \\
\hline R5 & $\begin{array}{l}\text { Tidak adanya lubang baut } \\
\text { dan tap pada bum }\end{array}$ & 4 & 9 & 5 & 180 \\
\hline R6 & $\begin{array}{l}\text { Spyged tidak masuk pada } \\
\text { alur }\end{array}$ & 4 & 8 & 5 & 160 \\
\hline \multirow{2}{*}{$\begin{array}{l}\text { R7 } \\
\text { R8 }\end{array}$} & Lubang stoper tidak halus & 4 & 6 & 7 & 168 \\
\hline & $\begin{array}{l}\text { Proses pembuatan filter } \\
\text { untuk oli yang memakan } \\
\text { waktu }\end{array}$ & 4 & 8 & 5 & 160 \\
\hline R9 & $\begin{array}{l}\text { Ukuran ulir pada baut bum } \\
\text { tidak sesuai }\end{array}$ & 4 & 5 & 6 & 120 \\
\hline $\mathrm{R} 10$ & $\begin{array}{l}\text { Bubutan kiri-kanan engkol } \\
\text { tidak sesuai titik pusat }\end{array}$ & 4 & 5 & 5 & 100 \\
\hline R11 & $\begin{array}{l}\text { Tidak adanya tap lubang } \\
\text { baut M8 dan M18 }\end{array}$ & 4 & 8 & 5 & 160 \\
\hline $\mathrm{R} 12$ & $\begin{array}{l}\text { Ulir macet pada bur } \\
\text { sloping diameter } 5\end{array}$ & 4 & 9 & 5 & 180 \\
\hline R13 & Jarak PCD tidak tepat & 5 & 7 & 5 & 175 \\
\hline R14 & $\begin{array}{l}\text { Lubang PCD tidak sesuai } \\
\text { dengan titik pusat }\end{array}$ & 5 & 7 & 5 & 175 \\
\hline R15 & $\begin{array}{l}\text { Ukuran lubang bus } \\
\text { pengangkat trenden } \\
\text { (kuningan) tidak sesuai }\end{array}$ & 4 & 8 & 5 & 160 \\
\hline R16 & $\begin{array}{l}\text { Permukaan di ulir trenden } \\
\text { bagian tengah kurang } \\
\text { rendah }\end{array}$ & 4 & 6 & 6 & 144 \\
\hline R17 & $\begin{array}{l}\text { Ukuran trenden tidak } \\
\text { sesuai (terlalu pas) }\end{array}$ & 4 & 6 & 6 & 144 \\
\hline R18 & $\begin{array}{l}\text { Kesulitan penyetelan gear } \\
\text { helix pada matras knee rest }\end{array}$ & 4 & 7 & 5 & 140 \\
\hline R19 & $\begin{array}{l}\text { Ketidaksesuaian dimensi } \\
\text { dan ukuran pada setelan } \\
\text { ulir pinggang }\end{array}$ & 5 & 8 & 5 & 200 \\
\hline R20 & $\begin{array}{l}\text { Ketidaklengkapan } \\
\text { standard part }\end{array}$ & 5 & 8 & 5 & 200 \\
\hline R21 & $\begin{array}{ll}\text { Ketidakcocokan } & \text { ukuran } \\
\text { baut (biasanya } & \text { terlalu } \\
\text { panjang) } & \end{array}$ & 4 & 5 & 4 & 80 \\
\hline R22 & $\begin{array}{l}\text { Sinkronisasi waktu datang } \\
\text { standard part yang tidak } \\
\text { tepat }\end{array}$ & 5 & 6 & 4 & 120 \\
\hline
\end{tabular}


Terdapat sejumlah 22 risiko yang teridentifikasi dengan nilai RPN yang beragam untuk setiap risiko. Risiko dengan nilai RPN yang besar akan menjadi prioritas mitigasi karena memiliki tingkat keparahan, dan kejadian yang tinggi, sehingga berpotensi untuk menyebabkan kerugian maupun penurunan produktivitas bagi perusahaan. Beberapa RPN dengan nilai besar antara lain terkait dengan risiko ketidaksesuaian part yang bisa menimbulkan pengerjaan ulang atau rework.

Setelah nilai severity dan occurence didapatkan, kemudian risiko yang teridentifikasi diplot ke dalam risk matrix atau peta risiko untuk mengetahui seberapa besar risiko yang ada pada objek yang dianalisis. Peta risiko berfungsi untuk menggambarkan sebaran risiko berdasarkan tingkat keparahan dan kejadian agar dapat dikategorikan menjadi beberapa prioritas penyelesaian atau mitigasi. Risk matrix ditunjukkan pada Gambar 2 berikut.

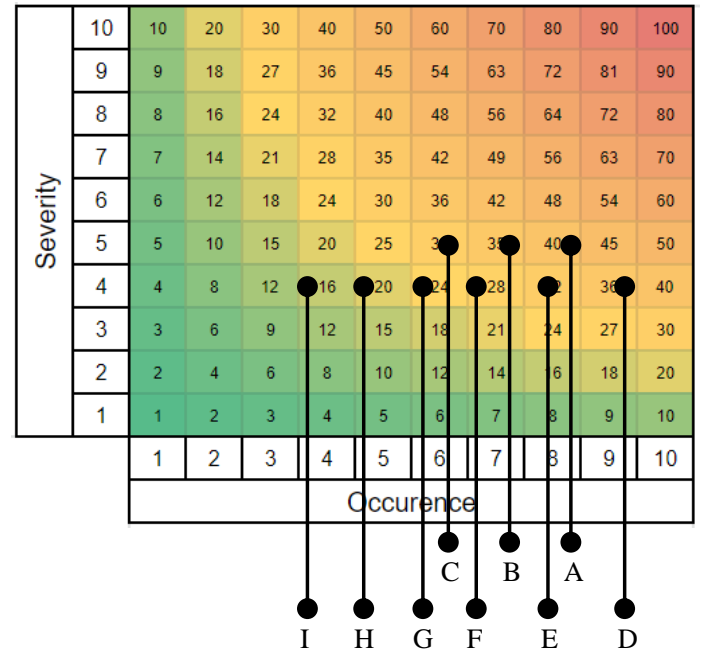

$A=R 19, R 20 ; \quad B=R 5, R 12 ; \quad C=R 13, R 14 ;$
$D=R 2, R 6, R 8, R 11, R 15 ; \quad E=R 22, \quad F=R 1, R 18 ;$
G=R7,R16,R17; $\quad$ H = R4,R9,R10,R21; $\quad I=R 3$

Gambar 2. Risk Matrix Pada Proses Assembly Produk Operating Table Manual

Berdasarkan risk matrix atau peta risiko di atas, dapat dilihat bahwa seluruh risiko yang telah teridentifikasi merupakan risiko dengan kategori sedang. Risiko dengan kategori sedang berarti berada dalam batas toleransi namun tetap direkomendasikan untuk dilakukan perbaikan. Hasil pemetaan di atas digunakan sebagai acuan tambahan dalam melakukan mitigasi risiko selain juga mempertimbangkan nilai RPN sebagai acuan utama prioritas perbaikan.

Langkah perbaikan ataupun mitigasi yang akan dilakukan sebagai tindak lanjut temuan risiko perlu dirancang sedemikian rupa agar kendala yang ditemukan dalam aktivitas tidak terulang kembali. Oleh karena itu, 22 risiko yang telah teridentifikasi sebelumnya kemudian dianalisis lebih lanjut sehingga dapat diketahui penyebab kemunculan atau risk cause dan potensi dampak atau potential effect yang diakibatkan oleh risiko-risiko tersebut. Hasil analisis penyebab kemunculan risiko (risk cause) beserta potensi dampak (potential effect) ditunjukkan pada Tabel VI dan VII berikut.

TABEL VI

HASIL ANALISIS RISK CAUSE

\begin{tabular}{|c|c|}
\hline $\begin{array}{l}\text { Kode } \\
\text { Risiko }\end{array}$ & Risk Cause \\
\hline R1 & Perubahan ukuran karena proses pengecatan \\
\hline $\mathrm{R} 2$ & Seal katub tidak tersedia di pasaran \\
\hline \multirow[t]{2}{*}{$\mathrm{R} 3$} & $\begin{array}{l}\text { Seal katub tidak presisi karena pembuatan secara } \\
\text { manual }\end{array}$ \\
\hline & Terdapat lubang pada material cor \\
\hline $\mathrm{R} 4$ & $\begin{array}{l}\text { Tertukarnya nomor urut material pada saat } \\
\text { bongkar muat material }\end{array}$ \\
\hline $\mathrm{R} 5$ & $\begin{array}{l}\text { Proses pengerjaan dilakukan di unit yang berbeda, } \\
\text { sehingga operator SPIKMA tidak berani spekulasi } \\
\text { ukuran }\end{array}$ \\
\hline R6 & $\begin{array}{l}\text { Spyged datang dengan ukuran berbeda sehingga } \\
\text { operator SPIKMA tidak berani melakukan } \\
\text { spekulasi ukuran }\end{array}$ \\
\hline \multirow[t]{2}{*}{ R7 } & Operator kurang teliti \\
\hline & $\begin{array}{l}\text { Pada gambar tidak ada keterangan untuk } \\
\text { menghaluskan }\end{array}$ \\
\hline $\mathrm{R} 8$ & $\begin{array}{l}\text { SDM tidak bersedia membuat filter karena beban } \\
\text { kerja yang sudah banyak }\end{array}$ \\
\hline R9 & Alat kerja yang digunakan sudah aus \\
\hline \multirow[t]{2}{*}{$\mathrm{R} 10$} & Pengerjaan secara manual \\
\hline & $\begin{array}{l}\text { Operator tidak membaca gambar dan melakukan } \\
\text { pengerjaan berdasarkan kebiasaan }\end{array}$ \\
\hline $\mathrm{R} 11$ & $\begin{array}{l}\text { Tingkat kepresisian untuk mengerjakan masih } \\
\text { belum optimal sehingga tidak berani, beda titik } \\
\text { pengeboran }\end{array}$ \\
\hline $\mathrm{R} 12$ & $\begin{array}{l}\text { Toleransi untuk bubut ulir dalam dan ulir luar } \\
\text { kurang besar }\end{array}$ \\
\hline $\mathrm{R} 13$ & $\begin{array}{l}\text { Kesalahan proses karena operator tidak membaca } \\
\text { gambar }\end{array}$ \\
\hline \multirow[t]{2}{*}{$\mathrm{R} 14$} & Pengerjaan secara manual dan alat tidak presisi \\
\hline & $\begin{array}{l}\text { Kesulitan pengerjaan karena bentuk material tidak } \\
\text { presisi }\end{array}$ \\
\hline $\mathrm{R} 15$ & $\begin{array}{l}\text { Kesalahan pada gambar dari engineering } \\
\text { Operator kurang teliti }\end{array}$ \\
\hline $\mathrm{R} 16$ & Dimensi ukuran cor tidak sesuai \\
\hline $\mathrm{R} 17$ & $\begin{array}{l}\text { Kesalahan pada gambar (tidak ada keterangan } \\
\text { untuk melakukan cemper) }\end{array}$ \\
\hline \multirow[t]{2}{*}{$\mathrm{R} 18$} & Tidak ada standarisasi dalam penyetelan gear \\
\hline & Tidak semua operator bisa melakukan penyetelan \\
\hline \multirow[t]{2}{*}{ R19 } & Gambar yang digunakan adalah gambar lama \\
\hline & Operator SPIKMA tidak membaca gambar \\
\hline \multirow[t]{3}{*}{ R20 } & BOM yang digunakan adalah BOM lama \\
\hline & Kesulitan mencari standart part di pasaran \\
\hline & $\begin{array}{l}\text { Sinkronisasi waktu datang standart part yang } \\
\text { tidak tepat }\end{array}$ \\
\hline $\mathrm{R} 21$ & $\begin{array}{l}\text { SCM memilih untuk pembelian partai besar } \\
\text { dengan ukuran yang berbeda }\end{array}$ \\
\hline $\mathrm{R} 22$ & Ketidaktepatan penjadwalan pre-order pada SCM \\
\hline
\end{tabular}


Tabel VI di atas terlihat bahwa sebagian besar risiko yang teridentifikasi disebabkan oleh kesalahan gambar dan juga supply material dan bahan dari SPIKMA yang merupakan anak perusahaan yang berperan sebagai penyedia material dan komponen. Selain itu, kesalahan gambar rancangan, human error, dan juga kendala peralatan merupakan hal-hal lain yang menjadi penyebab kemunculan risiko. Selanjutnya, hasil analisis dampak (potential effect) dari setiap risiko yang teridentifikasi ditunjukkan pada Tabel VII

TABEL VII

Hasil ANALISIS Potential EFFECT

\begin{tabular}{|c|c|}
\hline $\begin{array}{l}\text { Kode } \\
\text { Risiko }\end{array}$ & Potential Effect \\
\hline $\mathrm{R} 1$ & $\begin{array}{l}\text { Operator assembly harus melakukan tap ulang } \\
\text { pada katub pompa }\end{array}$ \\
\hline $\mathrm{R} 2$ & $\begin{array}{l}\text { Operator assembly harus membuat seal katub } \\
\text { secara manual }\end{array}$ \\
\hline $\mathrm{R} 3$ & $\begin{array}{l}\text { Operator assembly harus melakukan bongkar } \\
\text { pasang pompa }\end{array}$ \\
\hline $\mathrm{R} 4$ & $\begin{array}{l}\text { Operator assembly harus melakukan gerinda } \\
\text { ulang pada as dan bum }\end{array}$ \\
\hline R5 & $\begin{array}{l}\text { Operator assembly harus melakukan bor dan tap } \\
\text { ulang }\end{array}$ \\
\hline R6 & $\begin{array}{l}\text { Operator assembly harus melakukan gerinda } \\
\text { ulang pada alur atau bum }\end{array}$ \\
\hline R7 & $\begin{array}{l}\text { Operator assembly harus menghaluskan lubang } \\
\text { stoper }\end{array}$ \\
\hline $\mathrm{R} 8$ & $\begin{array}{l}\text { Operator assembly harus memotong filter secara } \\
\text { manual }\end{array}$ \\
\hline R9 & $\begin{array}{l}\text { Operator assembly harus melakukan senai pada } \\
\text { baut bum }\end{array}$ \\
\hline $\mathrm{R} 10$ & $\begin{array}{l}\text { Operator assembly harus melakukan rotari lubang } \\
\text { ulang pada engkol }\end{array}$ \\
\hline $\mathrm{R} 11$ & $\begin{array}{l}\text { Operator assembly harus melakukan pengeboran } \\
\text { dan tap ulang }\end{array}$ \\
\hline $\mathrm{R} 12$ & $\begin{array}{l}\text { Operator assembly harus melakukan pengerjaan } \\
\text { ulang }\end{array}$ \\
\hline $\mathrm{R} 13$ & $\begin{array}{l}\text { Adanya waktu tunggu material kembali dari } \\
\text { SPIKMA }\end{array}$ \\
\hline $\mathrm{R} 14$ & $\begin{array}{l}\text { Adanya waktu tunggu material kembali dari } \\
\text { SPIKMA }\end{array}$ \\
\hline $\mathrm{R} 15$ & $\begin{array}{l}\text { Operator assembly harus melakukan rotari lubang } \\
\text { ulang pada trenden }\end{array}$ \\
\hline $\mathrm{R} 16$ & $\begin{array}{l}\text { Operator assembly harus melakukan gerinda } \\
\text { ulang pada ulir }\end{array}$ \\
\hline $\mathrm{R} 17$ & Operator assembly harus melakukan cemper \\
\hline $\mathrm{R} 18$ & $\begin{array}{l}\text { Penyetelan gear helix pada matras knee rest hanya } \\
\text { dapat dilakukan oleh spesialis }\end{array}$ \\
\hline R19 & $\begin{array}{l}\text { Adanya waktu tunggu material kembali dari } \\
\text { SPIKMA }\end{array}$ \\
\hline R20 & $\begin{array}{l}\text { Pekerjaan terhambat karena standart part tidak } \\
\text { tersedia }\end{array}$ \\
\hline $\mathrm{R} 21$ & $\begin{array}{l}\text { Operator assembly harus melakukan pemotongan } \\
\text { baut }\end{array}$ \\
\hline $\mathrm{R} 22$ & $\begin{array}{l}\text { Pekerjaan terhambat karena standart part tidak } \\
\text { tersedia }\end{array}$ \\
\hline
\end{tabular}

Berdasarkan hasil analisis potential effect yang ditampilkan pada Tabel VII di atas, dapat dilihat bahwa aktivitas pekerjaan ulang atau rework menjadi potential effect yang paling banyak. Hal tersebut dapat diartikan bahwa aktivitas yang tidak bernilai tambah yang dihadapi oleh unit assembly adalah aktivitas rework. Selain itu, waktu tunggu dan ketidaktersediaan part juga menjadi potensi dampak yang ditumbulkan oleh risiko.

Proses mitigasi risiko merupakan tahapan akhir yang paling penting sebagai langkah perbaikan proses dalam mengurangi non value added activity. Dalam proses mitigasi, expert yang terlibat dalam proses identifikasi risiko juga dilibatkan dalam proses perencanaan usulan mitigasi dengan mempertimbangkan hasil analisis risk cause dan potential effect. Usulan tindakan mitigasi yang telah diurutkan berdasarkan prioritas perbaikan dapat dilihat pada tabel VIII di bawah ini.

TABEL VIII

USULAN MITIGASI RISIKO

\begin{tabular}{|c|c|c|}
\hline $\begin{array}{l}\text { Kode } \\
\text { Risiko }\end{array}$ & RPN & Usulan Mitigasi \\
\hline R1 & 224 & $\begin{array}{l}\text { Melakukan Quality Control (QC) } \\
\text { incoming material } \\
\text { Penutupan lubang pada saat proses } \\
\text { pengecatan }\end{array}$ \\
\hline R19 & 200 & $\begin{array}{l}\text { Revisi gambar } \\
\text { Perbaikan budaya kerja }\end{array}$ \\
\hline R20 & 200 & $\begin{array}{l}\text { Perbaikan penjadwalan pre-order } \\
\text { Revisi Bill of Material }\end{array}$ \\
\hline R5 & 180 & Penyediaan jig pengeboran \\
\hline R12 & 180 & $\begin{array}{l}\text { Memperbesar toleransi bubut menjadi } \\
0.02 \mathrm{~mm}\end{array}$ \\
\hline $\mathrm{R} 13$ & 175 & $\begin{array}{l}\text { Melakukan QC sebelum material } \\
\text { dikirimkan ke assembly } \\
\text { Perbaikan budaya kerja }\end{array}$ \\
\hline R14 & 175 & $\begin{array}{l}\text { Melakukan QC sebelum material } \\
\text { dikirimkan ke assembly } \\
\text { Melakukan pengecekan dan pengaturan } \\
\text { alat kerja yang sudah tidak layak } \\
\text { pakai/tidak presisi }\end{array}$ \\
\hline R7 & 168 & $\begin{array}{l}\text { Melakukan QC sebelum material } \\
\text { dikirimkan ke assembly } \\
\text { Pemberian keterangan tambahan untuk } \\
\text { menghaluskan pada gambar }\end{array}$ \\
\hline $\mathrm{R} 2$ & 160 & $\begin{array}{l}\text { Pencetakan lubang seal dilakukan untuk } \\
\text { mempercepat proses pembuatan seal } \\
\text { katub di assembly }\end{array}$ \\
\hline R6 & 160 & $\begin{array}{l}\text { Engineering melakukan revisi gambar } \\
\text { dengan mendetailkan ukuran } \\
\text { Perbaikan budaya kerja }\end{array}$ \\
\hline $\mathrm{R} 8$ & 160 & $\begin{array}{l}\text { Penyediaan alat kerja khusus pemotong } \\
\text { filter yang tidak mudah mengalami aus }\end{array}$ \\
\hline $\mathrm{R} 11$ & 160 & Pembuatan jig pengeboran \\
\hline R15 & 160 & $\begin{array}{l}\text { Revisi gambar } \\
\text { Melakukan QC sebelum material } \\
\text { dikirimkan ke assembly } \\
\text { Pembuatan jig }\end{array}$ \\
\hline R16 & 144 & $\begin{array}{l}\text { Melakukan QC sebelum material } \\
\text { dikirimkan ke assembly }\end{array}$ \\
\hline R17 & 144 & $\begin{array}{l}\text { Penambahan keterangan cemper pada } \\
\text { gambar }\end{array}$ \\
\hline
\end{tabular}




\begin{tabular}{|c|c|c|}
\hline \multirow{3}{*}{ R18 } & \multirow{3}{*}{140} & \multirow{3}{*}{$\begin{array}{l}\text { Perbaikan budaya kerja } \\
\text { Menetapkan standarisasi ukuran } \\
\text { Penjaminan ukuran komponen yang } \\
\text { datang selalu konsisten }\end{array}$} \\
\hline & & \\
\hline & & \\
\hline $\mathrm{R} 3$ & 128 & $\begin{array}{l}\text { Melakukan QC incoming material } \\
\text { untuk checking material cor }\end{array}$ \\
\hline $\mathrm{R} 4$ & 120 & $\begin{array}{l}\text { Pemberian kode urut berupa huruf pada } \\
\text { material }\end{array}$ \\
\hline \multirow[t]{2}{*}{ R9 } & 120 & $\begin{array}{l}\text { Melakukan QC sebelum material } \\
\text { dikirimkan ke assembly }\end{array}$ \\
\hline & & $\begin{array}{l}\text { Melakukan pengecekan dan pengaturan } \\
\text { alat kerja yang sudah tidak layak } \\
\text { pakai/tidak presisi }\end{array}$ \\
\hline R22 & 120 & Perbaikan penjadwalan pre-order \\
\hline R10 & 100 & $\begin{array}{l}\text { Melakukan QC sebelum material } \\
\text { dikirimkan ke assembly }\end{array}$ \\
\hline & & Perbaikan budaya kerja \\
\hline & & Pembuatan jig atau mal rotary \\
\hline $\mathrm{R} 21$ & 80 & Pekerjaan dialihkan ke PE \\
\hline
\end{tabular}

\section{IV.PEMBAHASAN}

Berdasarkan hasil penelitian yang telah didapatkan, diketahui bahwa tingginya persentase aktivitas non value added sebesar $30 \%$ dari total waktu siklus pada proses assembly produk operating table manual disebabkan oleh 22 risiko dengan berbagai tingkat gangguan maupun frekuensi. Penyebab terbesar munculnya 22 risiko tersebut berasal dari incoming material baik yang didapatkan dari tahap produksi di unit sebelumnya maupun material yang didapatkan dari vendor atau supplier. Penyebab tersebut terjadi karena vendor maupun supplier mengacu pada gambar rancangan part yang tersedia. Hal tersebut kemudian menjadi rekomendasi atau usulan mitigasi untuk 9 risiko (40\% dari seluruh risiko yang teridentifikasi) agar bisa dilakukan quality control yang lebih baik terhadap material yang didatangkan ke unit assembly khususnya untuk produk operating table manual.

Pemetaan risiko yang ditunjukkan dalam risk matrix memberikan informasi bahwa risiko-risiko yang terjadi umumnya tidak terlalu parah yang ditunjukkan dari nilai severity dengan batas atas adalah 5 dari skala 10 , namun yang menjadi permasalahan adalah tingkat occurence atau kejadian yang cukup sering terjadi. Hal tersebut ditunjukkan dari 22 risiko yang teridentifikasi, terdapat sebanyak $17(77 \%)$ risiko yang memiliki tingkat kejadian lebih dari skala 5. Berdasarkan kategori di dalam FMEA, skala lebih 5 menunjukkan bahwa risiko tersebut berada dalam tingkat yang moderat dan cenderung tinggi, yang apabila dikaitkan pada masalah yang dikaji dalam penelitian ini, bahwa teridentifikasi ada permasalahan yang sering berulang. Sumber masalah tersebut justru tidak terletak pada unit assembly yang diteliti melainkan pada unit sebelumnya maupun dari vendor sebagai sumber incoming material.

\section{KesimpULAN}

Aktivitas non value added merupakan salah satu risiko yang dihadapi oleh perusahaan dalam mencapai produktivitas yang lebih baik. Pada objek penelitian yang dikaji, yaitu unit assembly produk operating table manual, terdapat sebanyak 22 risiko yang sebagian besar memiliki tingkat gangguan di level medium, namun frekuensi kemunculannya berada pada tingkat moderat yang cenderung tinggi. Hal tersebut menunjukkan bahwa terdapat risiko yang sering muncul yang setelah dilakukan analisis berasal dari permasalahan yang berulang, seperti rework ataupun penyesuaian material yang bersumber dari unit sebelumnya maupun dari vendor karena ketidaksesuaian spesifikasi desain. Berdasarkan analisis risiko yang dilakukan, usulan perbaikan yang dapat diberikan untuk memitigasi $40 \%$ risiko yang ada adalah dengan menerapkan quality control yang lebih baik terhadap incoming material.

\section{REFERENSI}

[1] D. Pujotomo och D. N. Rusanti, "Usulan Perbaikan untuk Meningkatkan Produktivitas Filling Plant dengan Pendekatan Lean Manufacturing pada PT. SMART Tbk Surabaya,” Jurnal Teknik Industri, vol. X, 2015.

[2] C. Ashmore, "Kaizen-and The Art of Motorcycle Manufacture," Engineering Management Journal, vol. 11, nr 5, pp. 211-214, 2001.

[3] A. K. Dhingra, S. Kumal och B. Singh, "Cost reduction and quality improvement through Lean-Kaizen concept using value stream map in Indian manufacturing firms," International Journal of System Assurance Engineering and Management, vol. 10, nr 4, pp. 792-800, 2019.

[4] W. Shou, J. Wang, P. Wu och X. Wang, "Value Adding and Non-Value Adding Activities in Turnaround Maintenance Process: Classification, Validation, and Benefits," Production Planning \& Control, vol. 31, nr 1, pp. $60-77,2020$

[5] R. Griffin, Fundamentals of Management, Nelson Education, 2013.

[6] C. Harland, R. Brenchley och H. Walker, "Risk in Supply Network," Journal of Purchasing and Supply Management, vol. 9, nr 2, pp. 51-62, 2003.

[7] R. J. Mikulak, R. McDermott och M. Beauregard, The Basic of FMEA, CRC Press, 2017.

[8] H.-C. Liu, FMEA using uncertainty theories and MCDM methods., Singapore: Springer, 2016, pp. 13-27.

[9] W. Jiang, C. Xie, M. Zhuang och Y. Tang, "Failure mode and effects analysis based on a novel fuzzy evidential method.," Applied Soft Computing, vol. 57, pp. 672-683, 2017. 
[10] H. Firdaus och T. Widianti, "Failure mode and effect analysis (FMEA) sebagai Tindakan Pencegahan pada Kegagalan Pengujian,” Lembaga Ilmu Pengetahuan Indonesia, Pusat Penelitian Sistem Mutu dan Teknologi Pengujian, Banten, 2015.

[11] T. Henkey, Urban emergency management: planning and response for the 21st Century, Butterworth-Heinemann, 2017. 